\title{
DESEMPENHO DE NOVILHOS NELORE E SEUS MESTIÇOS COM SANTA GERTRUDIS E SIMENTAL, RECEBENDO CINCO NÍVEIS DE SUPLEMENTAÇÃO A PASTO ${ }^{1}$
}

\author{
Performance of Nelore steers and its crossbreeds with Santa Gertrudis and Simental, \\ receiving five different supplementation levels
}

\author{
Rafael Henrique de Tonissi e Buschinelli de Goes ${ }^{2}$, Antonio Bento Mancio ${ }^{3}$, Dorismar David Alves 4 , \\ Rogério de Paula Lana ${ }^{3}$, Daniel Moreira Lambertucci ${ }^{4}$, Alonso Thiago Silvestre da Silva ${ }^{5}$
}

\begin{abstract}
RESUMO
Este trabalho teve como objetivo avaliar o desempenho e a eficiência suplementar de novilhos Nelore e seus mestiços com Santa Gertrudis e Simental, mantidos em pasto de Brachiaria brizantha durante a recria e recebendo diferentes níveis de suplementação, entre os meses de março e novembro de 2003. Foram utilizados novilhos de três grupos genéticos, com idade média de 10 meses, e peso de $226 \mathrm{Kg}$; em delineamento inteiramente casualizado. Os tratamentos utilizados foram baseados no fornecimento de suplementos nas quantidades de $0,125 \%, 0,25 \%, 0,50 \%$ e $1,0 \%$ do peso vivo, e controle (Sal Mineral). Todos os tratamentos tiveram como base o milho e o farelo de soja, com teor de $24 \%$ de proteína bruta. Não ocorreram diferenças entre os grupos genéticos dentro de um mesmo nível de fornecimento, mas sim entre os níveis. Todos os animais responderam a suplementação com aumento de peso, não ocorrendo diferença entre os níveis de 0,5\% e 1,0\% de suplemento. Apesar do suplemento afetar positivamente o ganho de peso dos animais durante os períodos, a resposta para níveis mais altos de suplementação foi ineficiente em todos os grupos genéticos estudados. A pior eficiência apresentada pelos animais da raça Nelore, na época de transição pode estar associada a menor ingestão de matéria seca. Durante a época seca os mestiços Nelore/Santa Gertrudis, e Nelore/Simental, responderam com 0,10 quilo de ganho/animal/dia para cada quilo de suplemento no nível de 1,0\%. Os melhores resultados parecem ter ocorrido quando se forneceu uma pequena quantidade de suplemento 0,125\% do PV, e os animais se mostraram extremamente eficiente, com eficiências médias de 1,62.
\end{abstract}

Termos para indexação: Amazônia, eficiência do suplemento, Nelore, raças, Nelore x Santa Gertrudis, Nelore x Simental.

\begin{abstract}
The objective of this experiment was to evaluate the performance and the supplementary effectiveness of Nellore steers and its crossbreeds with Santa Gertudris and Simental, grazing Brachiaria brizantha pasture during the post-weaning period and receiving different levels of supplementation, between the months of March and November of 2003. Three different genetic groups were used. The initial average live weight $226 \mathrm{was} \mathrm{kg}$, and 10 months of age, in randomized design. The treatments tested were control (mineral salt) and supplements furnished at the levels of $0.125 \%, 0.25 \%, 0.50 \%$, and $1.0 \%$ of the body weight/animal/day. All the treatments were based on corn and soybean meal, with $24 \%$ of crude protein. There were no differences among the genetic groups in the same level of supply, but there were differences due to the levels. All the animals increased the weight gain, with the supply, and there were no differences between the supplementation levels at the $0.5 \%$ and $1.0 \%$. In spite of the positive effect of the supplement in the weight gain of the animals during the periods, the response to the higher levels of supplies was ineffective in all the genetic groups studied. The lower response, presented by the Nellore animals, in the transition period, may be related to the fact that they showed a lower dry matter intake. During the dry period, the Santa Gertrudis and Simental x Nellore crossbreed animals shown weight gain of 0.10 kilos per animal per day for each kg of supplement for the supply at the level of $1.0 \%$ of their body weight. The best results seem to appear when a small quantity of supply $0.125 \%$ of their live weight, where the animals were extremely effective, with efficiency rates of 1.62 .
\end{abstract}

Index terms: amazonia, supplemental efficiency, Nellore, breed, Nellore x Santa Gertrudis, Nellore x Simental.

(Recebido para publicação em 27 de janeiro de 2005 e aprovado em 10 de junho de 2005)

\section{INTRODUÇÃO}

O aumento da competitividade com outras carnes, bem como com outros mercados e a estabilidade do Brasil nas exportações mundiais de carne bovina, desafia a atividade pecuária de corte a produzir de forma eficiente. A inserção brasileira no mercado internacional é dependente de dois aspectos: constância de oferta e uniformidade na qualidade de carne. Com isso, a fase de recria, contribuindo com aproximadamente 58\%, de todo processo produtivo é

\footnotetext{
${ }^{1}$ Parte do projeto financiado pelo CNPq.

2Zootecnista, DS, Professor do Curso de Medicina Veterinária/UEM - Campus Regional de Umuarama,PR - rgoes@elitnet.com.br - rhtbg@uol.com.br 3Professores do DZO/UFV - Viçosa,MG - 36571-000 - amancio@ufv.br - rlana@ufv.br

${ }^{4}$ Estudantes de Pós-Graduação - DZO/UFV - Viçosa,MG - 36571-000

${ }^{5}$ Estudante de Pós-Graduação/UEMS - Aquidauana,MS - 79200-000 - alonsoss@terra.com.br
} 
fundamental para o estabelecimento da idade de abate. Esta desempenha um importante papel dentro deste contexto, uma vez que animais mais jovens possuem uma tendência de produzir carne mais macia.

$\mathrm{O}$ abate de animais jovens denominados superprecoces, com idade aproximada de 12 meses e aqueles considerados precoces, abatidos com até dois anos de idade, são os principais responsáveis pelo fornecimento de produtos de qualidade ao longo do ano. A utilização de estratégias alimentares como a suplementação de bovinos mantidos em pastagens durante as diferentes épocas do ano e o semiconfinamento, bem como a utilização do potencial genético dos animais, através de cruzamentos e o abate de machos e fêmeas para a produção de carne, são soluções que garantem a oferta dos animais e a rentabilidade dos sistemas de produção.

A utilização de animais que possuem diferentes taxas de maturação pode se constituir em uma estratégia importante (EUCLIDES FILHO, 2000). Neste sentido, os cruzamentos entre raças com combinação de diferentes taxas de crescimento se torna uma alternativa viável para produção de carne. Animais resultantes do cruzamento de raças adaptadas, principalmente as zebuínas, com raças européias adaptadas ou não, podem melhorar não só o desempenho, mas a qualidade de carcaça e em particular a sua conformação (EUCLIDES FILHO et al., 1997, 2002).

Outra alternativa que merece avaliação é o controle de ingestão de alimentos que tem se mostrado capaz de produzir carne bovina de forma bioeconomicamente eficiente (EUCLIDES FILHO et al., 2003). Este controle pode ser realizado tanto pela restrição alimentar e subseqüente capitalização no ganho compensatório, como pela diminuição da densidade energética da dieta de parte dos animais. Quanto à primeira maneira, ou seja, uso do ganho compensatório, resultados de vários trabalhos têm possibilitado concluir que a restrição na ingestão de alimentos resulta em maiores taxas de crescimento durante o período de realimentação quando comparados com animais que foram alimentados normalmente. No entanto, esta estratégia deve ser analisada cuidadosamente, uma vez que, esse ganho compensatório é, na maioria das vezes, parcial (EUCLIDES et al., 1998).

Este trabalho tem como objetivo avaliar o desempenho e a eficiência suplementar de novilhos Nelore e seus mestiços com Santa Gertrudis e Simental, mantidos a pasto recebendo diferentes níveis de suplementação, na região Amazônica.

\section{MATERIAL E MÉTODOS}

O trabalho foi desenvolvido entre os meses de março a novembro de 2003 na Fazenda Rancho SS, no município de Alta Floresta - MT, localizado a 9 53'02" de latitude sul, $56^{\circ} 14^{\prime} 38^{\prime \prime}$ de longitude oeste, na altitude de $288 \mathrm{~m}$. O clima predominante é o equatorial úmido e quente, com uma nítida estação seca e temperatura anual média de $26^{\circ} \mathrm{C}$ com uma precipitação de $2750 \mathrm{~mm}$ por ano.

O experimento foi implantado em uma área de 24,5 ha, com pastagem de braquiária (Brachiaria brizantha cv. Marandu), sem adubação ou outra prática de manejo, sendo pastejada desde a sua implantação, e dividida em cinco piquetes, com cochos cobertos de duplo acesso e "aguadas".

Foram utilizados novilhos de três grupos genéticos, sendo 15 1/2 Santa Gertrudis x Nelore, 15 1/2 Simental x Nelore e 15 Nelores, com idade média de 10 meses, e peso médio inicial de $226 \mathrm{Kg}$. Os animais foram identificados, pesados e distribuídos, de forma homogênea e aleatória nos piquetes, a fim de se garantir as médias de peso vivo e os grupos genéticos semelhantes entre os tratamentos. As pesagens foram feitas a cada 21 dias.

Antes do experimento os animais foram mantidos em pastagem de Brachiaria brizantha, apenas com suplementação mineral. Todos os animais foram vacinados contra febre aftosa e desverminados com vermífugo a base de Moxidectina a $1 \%\left(\right.$ Cydectin $\left.^{\hat{a}} \mathrm{NF}\right)$. A vermifugação repetiu-se a cada 60 dias, e o controle da mosca do chifre foi realizado com o uso de inseticidas a base de cipermetrina e organofosforados, a cada 21 dias, de acordo com as necessidades.

Os suplementos foram fornecidos com base no peso vivo dos animais, nas quantidades de $0,125 \%, 0,25 \%$, $0,5 \%$ e $1,0 \% \mathrm{PV}$, mais o grupo controle que recebeu apenas suplementação mineral. Nas Tabelas 1, 2 e 3 estão descritos os suplementos utilizados.

A conversão de ganho para os suplementos foi calculada em função do consumo de suplemento apresentado pelos animais dividido pelo diferencial de ganho de peso em relação à suplementação mineral.

A disponibilidade da forrageira foi determinada no $1^{\circ}$ dia do experimento, pelo corte de 10 áreas tomadas aleatoriamente e delimitadas por um quadrado metálico, de $0,5 \times 0,5 \mathrm{~m}\left(0,25 \mathrm{~m}^{2}\right.$ de área), por piquete. As amostras foram separadas em duas porções, para a avaliação da disponibilidade de matéria seca (MS) e das frações folha, colmo e material morto.

Ciênc. agrotec., Lavras, v. 29, n. 6, p. 1265-1271, nov./dez., 2005 
TABELA 1 - Composição (\%) dos suplementos fornecidos aos animais, em diferentes níveis.

\begin{tabular}{lllll}
\hline & \multicolumn{4}{c}{ Fornecimento do Suplemento (\%) PV) } \\
\cline { 2 - 5 } Ingrediente (\%) & $\mathbf{0 , 1 2 5}$ & $\mathbf{0 , 2 5}$ & $\mathbf{0 , 5 0}$ & $\mathbf{1 , 0}$ \\
\hline Milho grão & 53,47 & 68,64 & 77,75 & 81,20 \\
Farelo de soja & 10,00 & 10,00 & 10,00 & 10,00 \\
Amiréia 180 & 6,10 & 6,60 & 6,92 & 6,94 \\
Sal (NaCl) & 15,00 & 7,50 & 3,00 & 1,00 \\
Fosfato bicálcico & 5,79 & 2,48 & 0,49 & - \\
Premix mineral & 2,00 & 1,00 & 0,40 & 0,20 \\
Calcário calcítico & 7,68 & 3,78 & 1,44 & 0,66 \\
\hline
\end{tabular}

TABELA 2 - Composição percentual do suplemento mineral utilizado e custo (R\$) por quilo de produto

\begin{tabular}{lc}
\hline Ingrediente & Mistura mineral (\%) \\
\hline Fosfato bicálcico & 44,44 \\
Calcário & 14,82 \\
Sal & 37,72 \\
Sulfato de cobre & 0,57 \\
Sulfato de manganês & 0,40 \\
Óxido de zinco & 0,68 \\
Sulfato de cobalto & 0,05 \\
Iodato de cálcio & 0,013 \\
Enxofre ventilado & 1,30 \\
Selenito de sódio & 0,006 \\
\hline Custo $(\mathrm{r} \$)$ & 0,51 \\
\hline
\end{tabular}

TABELA 3 - Composição químico-bromatológica dos suplementos utilizados, para novilhos mantidos a pasto, durante o período experimental

\begin{tabular}{lccccc}
\hline & \multicolumn{5}{c}{ Fornecimento do suplemento (\% PV) } \\
\cline { 2 - 6 } & SM & $\mathbf{0 , 1 2 5}$ & $\mathbf{0 , 2 5}$ & $\mathbf{0 , 5 0}$ & $\mathbf{1 , 0 0}$ \\
\hline PB (\%) & - & 24,0 & 24,0 & 24,0 & 24,0 \\
FDN (\%) & - & 14,50 & 16,6 & 25,5 & 27,1 \\
EE (\%) & - & 2,47 & 1,93 & 3,06 & 3,26 \\
NDT - (\%) & - & 52,7 & 65,02 & 72,42 & 75,19 \\
Cinzas - (\%) & 85,86 & 24,73 & 12,27 & 5,50 & 3,20 \\
Ca (\%) & 18,72 & 3,0 & 1,5 & 0,60 & 0,50 \\
P (\%) & 8,72 & 2,0 & 1,0 & 0,40 & 0,23 \\
Na (\%) & 13,98 & 5,56 & 2,78 & 1,12 & 0,38 \\
Mg (\%) & 1,14 & 0,57 & 0,34 & 0,2 & 0,16 \\
S (\%) & 1,50 & 0,61 & 0,38 & 0,24 & 0,19 \\
Cu (ppm) & 1450,0 & 335,42 & 170,93 & 72,24 & 39,35 \\
Mn (ppm) & 1250,0 & 84,99 & 45,61 & 21,98 & 14,13 \\
Zn (ppm) & 5000,0 & 1008,05 & 509,56 & 210,48 & 110,82 \\
Co (ppm) & 100,0 & 28,03 & 14,04 & 5,64 & 2,84 \\
I (ppm) & 80,0 & 15,06 & 7,56 & 3,09 & 1,59 \\
Se (ppm) & 28,0 & 2,04 & 1,04 & 0,44 & 0,25 \\
F (ppm) & 800,0 & 241,09 & 103,22 & 20,51 & - \\
\hline SM & \multicolumn{4}{c}{} \\
\hline
\end{tabular}

$\mathrm{SM}=$ suplementação Mineral.

${ }^{1} \mathrm{NDT}=\mathrm{PBD}+2,25 \mathrm{EED}+\mathrm{FDNcpD}+\mathrm{CNFD}-7 ; \mathrm{PBD}=\mathrm{PB} * \exp [-1,2 *(\mathrm{PIDA} / \mathrm{PB})] ; \mathrm{EED}=\mathrm{EE}-1 ; \mathrm{FDNcp}=0,75 *(\mathrm{FDN}-$ Lignina) $*\left[1-(\text { lignina/FDN })^{0,667}\right) ; \mathrm{CNFD}=0,98 *(100-[(\mathrm{FDN}-\mathrm{PIDN})+\mathrm{PB}+\mathrm{EE}+\mathrm{CZ}]$ 
Todas as amostras foram armazenadas em sacos plásticos previamente identificadas, congeladas à $-10^{\circ} \mathrm{C}$ e transportadas para o Laboratório de Nutrição Animal da Universidade Federal de Viçosa, para análises laboratoriais futuras.

Após serem descongeladas à temperatura ambiente e secas em estufa ventilada a $65^{\circ} \mathrm{C}$, por 72 horas foram processadas em moinhos do tipo Willey, peneira de malha $1 \mathrm{~mm}$, e determinado os teores de proteína bruta (PB) e extrato etéreo (EE), fibra em detergente neutro (FDN) e fibra em detergente ácido (FDA), cinzas e minerais conforme descrito por Silva \& Queiroz (2002). A digestibilidade in vitro da matéria seca (DIVMS) foi determinada segundo Tilley \& Terry (1963) modificado.

$\mathrm{O}$ delineamento experimental foi inteiramente casualizado (DIC), e o modelo utilizado Yij $=\mu$ r Ti $+\mathrm{Rj}+$ eij. Em que Yij é variável observada: $\mu$, constante geral; Ti, efeito do tratamento; Rj, efeito da raça; eij, erro aleatório associado a cada observação. Os dados foram analisados por meio da análise de variância conforme o programa estatístico SAEG (UFV, 2000). As médias de ganho de peso foram comparadas pelo teste de Tukey, a $5 \%$ de probabilidade.

\section{RESULTADOS E DISCUSSÃO}

Todos os animais tiveram acesso a alta disponibilidade de pasto, o que garantiu a seletividade por parte deles. De acordo com Euclides et al. (1998), esta deve ser de 2,5 Ton MS/ha. Os dados referentes à disponibilidade, percentagem de caule, folhas e material morto, e altura da pastagem em função dos tratamentos estão na Tabela 4.

Não ocorreram diferenças entre os grupos genéticos dentro de um mesmo nível de fornecimento, mas sim entre os níveis. (Tabelas 5 e 6).

Todos os animais responderam com aumento de peso a suplementação, não ocorrendo diferença entre os níveis de fornecimento de $0,5 \%$ e $1,0 \%$ do PV. Machos por apresentarem uma maior exigência protéica para ganho de peso, selecionam dietas com maiores níveis de proteína, o que justifica uma maior procura deste por suplemento (DETMANN et al., 2002; FORBES, 1995).

Condições como falta de alimento, altas temperaturas, incidência solar direta e falta de parasitas, acarretam diferenças nas taxas de crescimento entre animais de diferentes grupos genéticos, decorrentes de alterações no consumo voluntário dos animais (FRISCH \& VERCOE, 1977). Detmann et al. (2002) demonstraram que animais zebuínos possuem um consumo de suplemento inferior aos animais europeus e seus mestiços; em função de apresentarem uma maior capacidade de digestão de forrageiras de baixa qualidade, decorrentes de uma capacidade para manter elevados níveis de amônia no interior do rúmen, e de um menor tempo de retenção da digesta (HUNTER \& SIEBERT, 1985a, b), isto pode ter provocado a pior eficiência apresentada pelos animais da raça Nelore, para o período de transição, em função da menor ingestão de matéria seca.

TABELA 4 - Disponibilidade (Ton MS/ha), percentagem de folhas caules e material morto da Brachiaria brizantha cv. Marandu e sua composição químico-bromatológica

\begin{tabular}{lc}
\hline Disponibilidade no início do experimento (Ton MS/ha) & 9,35 \\
Folhas (\%) & 19,22 \\
Caule (\%) & 67,43 \\
Material morto (\%) & 13,35 \\
\hline PB (\%) & 5,07 \\
FDN (\%) & 74,61 \\
FDA (\%) & 45,07 \\
DIVMS (\%) & 51,23 \\
Cinzas (\%) & 8,19 \\
Ca (\%) & 0,28 \\
P (\%) & 0,20 \\
CHOT $(\%)^{1}$ & 85,13 \\
NDT/PB & 10,10 \\
\hline
\end{tabular}

$\mathrm{PB}=$ Proteína bruta; FDN = fibra em detergente neutro; FDA = fibra em detergente ácido; DIVMS = digestibilidade in vitro da matéria seca, $\mathrm{CHOT}=$ carboidratos totais $(100-\% \mathrm{~PB}+\% \mathrm{EE}+\% \mathrm{CZ})$.

Ciênc. agrotec., Lavras, v. 29, n. 6, p. 1265-1271, nov./dez., 2005 
TABELA 5 - Médias e coeficiente de variação (CV\%), para PVI - peso vivo inicial (kg) e PVF - peso vivo final (kg) e CS consumo de suplemento $(\mathrm{kg} / \mathrm{d})$, de novilhos Nelore e seus mestiços com Santa Gertrudis e Simental, recriados a pasto

\begin{tabular}{|c|c|c|c|c|c|c|c|c|c|}
\hline \multirow[b]{2}{*}{ Suplemento (\%PV) } & \multicolumn{3}{|c|}{ Nelore } & \multicolumn{3}{|c|}{$\begin{array}{l}\text { F1 Nelore x Santa } \\
\text { Gertrudis }\end{array}$} & \multicolumn{3}{|c|}{ F1 Nelore x Simental } \\
\hline & $\begin{array}{l}\text { PVI } \\
(\mathrm{kg})\end{array}$ & $\begin{array}{l}\text { PVF } \\
(\mathrm{kg})\end{array}$ & $\begin{array}{c}\mathrm{CS} \\
(\mathrm{kg} / \mathrm{d})\end{array}$ & $\begin{array}{l}\text { PVI } \\
(\mathrm{kg})\end{array}$ & $\begin{array}{l}\text { PVF } \\
(\mathrm{kg})\end{array}$ & $\begin{array}{c}\mathrm{CS} \\
(\mathrm{kg} / \mathrm{d})\end{array}$ & $\begin{array}{l}\text { PVI } \\
(\mathrm{kg})\end{array}$ & $\begin{array}{l}\text { PVF } \\
(\mathrm{kg})\end{array}$ & $\begin{array}{c}\mathrm{CS} \\
(\mathrm{kg} / \mathrm{d})\end{array}$ \\
\hline $0,125 \%$ & 236,30 & 327,33 & 0,35 & 232,50 & 320,40 & 0,34 & 227,00 & 276,50 & 0,31 \\
\hline $0,25 \%$ & 211,60 & 295,50 & 0,64 & 228,90 & 351,80 & 0,73 & 219,75 & 351,80 & 0,71 \\
\hline $0,50 \%$ & 191,83 & 299,33 & 1,23 & 250,75 & 391,50 & 1,61 & 231,83 & 352,33 & 1,46 \\
\hline $1,00 \%$ & 206,75 & 341,00 & 2,74 & 214,08 & 349,83 & 2,82 & 246,67 & 388,67 & 3,18 \\
\hline Sal Mineral & 233,00 & 294,00 & - & 226,50 & 277,50 & - & 224,35 & 278,00 & - \\
\hline $\mathrm{CV} / \mathrm{PVI}$ & & & & & 10,66 & & & & \\
\hline $\mathrm{CV} / \mathrm{PVF}$ & & & & & 13,26 & & & & \\
\hline
\end{tabular}

TABELA 6 - Médias e coeficiente de variação (CV\%), para GDP - ganho de peso médio ( $\mathrm{kg} / \mathrm{dia})$ e eficiência do suplemento (ES)* de novilhos Nelore e seus mestiços com Santa Gertrudis e Simental, recriados a pasto

\begin{tabular}{|c|c|c|c|c|c|c|}
\hline \multirow{2}{*}{$\begin{array}{l}\text { Período de transição } \\
\text { Suplemento (\%PV) }\end{array}$} & \multicolumn{2}{|c|}{ Nelore } & \multicolumn{2}{|c|}{$\begin{array}{l}\text { F1 Nelore x Santa } \\
\text { Gertrudis }\end{array}$} & \multicolumn{2}{|c|}{ F1 Nelore x Simental } \\
\hline & $\begin{array}{c}\text { GDP } \\
(\mathrm{kg} / \mathrm{d})\end{array}$ & $\mathrm{ES}$ & GDP (kg/d) & ES & GDP $(\mathrm{kg} / \mathrm{d})$ & ES \\
\hline $0,125 \%$ & $0,50 \mathrm{~b}$ & 3,10 & $0,49 \mathrm{c}$ & 1,21 & $0,50 \mathrm{bc}$ & 1,18 \\
\hline $0,25 \%$ & $0,57 \mathrm{ab}$ & 3,22 & $0,74 a b$ & 1,18 & $0,58 \mathrm{abc}$ & 1,63 \\
\hline $0,50 \%$ & $0,77 \mathrm{a}$ & 2,97 & $0,76 a b$ & 2,56 & $0,72 \mathrm{ab}$ & 2,67 \\
\hline $1,00 \%$ & $0,82 \mathrm{a}$ & 5,58 & $0,83 \mathrm{a}$ & 4,00 & $0,88 \mathrm{a}$ & 4,35 \\
\hline $\mathrm{SM}^{\#}$ & $0,39 \mathrm{~b}$ & - & $0,21 \mathrm{c}$ & - & $0,23 \mathrm{c}$ & - \\
\hline CV/GDP (\%) & & & & 25,84 & & \\
\hline \multicolumn{7}{|l|}{ Período de seca } \\
\hline $0,125 \%$ & $0,61 \mathrm{a}$ & 1,0 & $0,51 \mathrm{ab}$ & 1,77 & $0,54 a b$ & 1,46 \\
\hline $0,25 \%$ & $0,42 \mathrm{ab}$ & 3,83 & $0,59 \mathrm{ab}$ & 2,57 & $0,55 \mathrm{ab}$ & 2,92 \\
\hline $0,50 \%$ & $0,41 \mathrm{ab}$ & 8,24 & $0,73 a$ & 4,03 & $0,56 a b$ & 6,23 \\
\hline $1,00 \%$ & $0,59 \mathrm{ab}$ & 8,80 & $0,60 \mathrm{a}$ & 10,19 & $0,63 \mathrm{a}$ & 10,73 \\
\hline SM & $0,24 \mathrm{~b}$ & - & $0,29 \mathrm{c}$ & - & $0,30 \mathrm{ab}$ & - \\
\hline CV/GDP (\%) & & & & 25,80 & & \\
\hline
\end{tabular}

Médias na coluna seguidas de letras diferentes diferem entre si $(\mathrm{P}<0,05)$ pelo teste Tukey.

\# SM = Sal mineral.

* Conversão de ganho calculada como quilogramas de suplemento fornecido diariamente dividido pelo ganho acima daquele da suplementação mineral.

Euclides Filho et al. (2001) ressaltam que independente da dieta utilizada; animais mestiços apresentam melhores desempenhos do que o Nelore. Neste trabalho os animais da raça Nelore apresentaram desenvolvimento e eficiência de utilização dos suplementos semelhantes para todos os níveis de suplementação fornecidos (Tabela 6).

Diferenças entre desempenhos nutricionais não são esperadas, Euclides Filho et al. (1997, 2002), não encontraram diferenças de conversão entre animais F1 Angus-Nelore e Simental-Nelore. Entretanto divergências, segundo Vercoe (1967) são bastante comuns entre estudos para a avaliação de eficiência alimentar envolvendo zebuínos e taurinos. Apesar do suplemento afetar positivamente o ganho de peso dos animais durante os períodos, a resposta para níveis altos de suplementação 
foi ineficiente em todos os grupos genéticos estudados. O aumento da quantidade de suplemento fornecida proporcionou uma pequena relação com o ganho de peso apresentado.

Uma eficiência inferior a 3:1 seria sintoma de deficiência de nitrogênio na pastagem (MCCOLLUM $\&$ HORN, 1990), com isso a maior resposta poderia ser atribuída ao fornecimento de proteína pelo suplemento, proporcionando o efeito positivo; similar aos resultados obtidos para os níveis mais baixos de suplementação. Já uma eficiência igual ou maior que 8:1 seria típica de uma suplementação energética, apresentando sintomas de substituição, ou uma ineficiência de utilização dos nutrientes presentes no suplemento, proporcionando assim um efeito associativo negativo (BODINE \& PURVIS, 2003), o que pode ter acarretado as piores eficiências para o nível de 1,0\% PV de fornecimento do suplemento.

A pastagem de Brachiaria brizantha disponível apresentou relação NDT:PB de 10,10 (Tabela 4). Valores superiores a 7,0 indica um déficit de proteína em relação à energia (MOORE et al., 1999). Nesse caso o fornecimento de pequenas quantidades de proteínas podem levar à melhora na performance animal, o que pode explicar a maior eficiência de ganho para os animais que receberam menores níveis de suplementação.

Durante a época seca onde os animais $1 / 2$ sangue Santa Gertrudis e $1 / 2$ sangue Simental responderam com 0,10 quilo de ganho/animal/dia para cada quilo de suplemento fornecido no nível de 1,0\% PV. Lana (2000) e Lana \& Gomes Júnior (2002), analisando dados de 25 publicações entre os anos de 1989 e 1995, encontraram eficiência para animais a pasto de 14,2 e de 10,1.

Capelle et al. (2001), avaliando o consumo e o ganho de peso, constataram uma eficiência de 9,0 para Nelore e 10,41 para seus mestiços com raças européias, com ganhos de peso de 0,85 e 1,00 kg/dia, semelhante ao apresentado no nível de 1,0\% PV de fornecimento. Backes et al. (2001), determinaram que animais Santa Gertrudis, possuem relação de $7,44 \mathrm{~kg}$ de $\mathrm{MS} / \mathrm{kg}$ de ganho porém para animais confinados.

Os melhores resultados parecem ser quando se fornece uma pequena quantidade de suplemento $0,125 \%$ $\mathrm{PV}$, onde os animais se mostraram extremamente eficiente, com conversões médias entre os grupos de 1,62. Euclides Filho et al. (2003), encontraram que o fornecimento de menor teor de concentrado para animais confinados pode ser uma alternativa para ampliar a oferta de carne, em função de uma maior eficiência bionutricional.
A suplementação para todos os grupos genéticos proporcionou respostas em ganhos de peso quando foram fornecidos suplementos com proteína, e baixa para uma suplementação energética, indicando que o nitrogênio não foi deficiente em relação à suplementação energética $(0,5 \%$ e $1,0 \% \mathrm{PV})$.

\section{CONCLUSÕES}

Os diferentes grupos genéticos não foram influenciados pelos níveis de suplemento, e apresentaram o melhor desempenho e maior eficiência de uso do suplemento para o nível de fornecimento de $0,125 \%$ do peso vivo.

\section{AGRADECIMENTOS}

Ao Sr. Pedro Silvestre Silva e ao Sr. Mário Wolf Filho, que tornou este trabalho possível, fornecendo os animais e os componentes da ração necessárias para a sua condução.

\section{REFERÊNCIAS BIBLIOGRÁFICAS}

BACKES, A. A.; SANCHEZ, L. M. B.; GONÇALVES, M. B. F. Desempenho de novilhos Santa Gertrudis confinados submetidos a dietas com diferentes fontes de protéicas e silagem de milho, com ou sem inoculante. Revista Brasileira de Zootecnia, Viçosa, v. 30, n. 6S, p. 21212125, 2001.

BODINE, T. N.; PURVIS, H. T. Effects of supplemental energy and/or degradable intake protein on performance, grazing behavior, intake, digestibility, and fecal and blood indices by beef steers grazed on dormant native tallgrass prairie. Journal of Animal Science, Champaign, v. 81, p. 304-317, 2003.

CAPELLE, E. R.; VALADARES FILHO, S. C.; SILVA, J. F. C. Estimativas do consumo e do ganho de peso de bovinos em condições brasileiras. Revista Brasileira de Zootecnia, Viçosa, v. 30, n. 6, p. 1857-1865, 2001.

DETMANN, E.; ZERVOUDAKIS, J. T.; PAULINO, M. P. Avaliação da influência de fatores de animal e meio sobre o consumo de suplementos múltiplos por bovinos em pastejo. In: REUNIÃO ANUAL DA SOCIEDADE BRASILEIRA DE ZOOTECNIA, 39., 2002, Recife. Anais... Recife: SBZ, 2002. CD-ROM.

EUCLIDES FILHO, K. Produção de bovinos de corte e o trinômio genótipo ambiente mercado. Campo Grande: EMBRAPA Gado de Corte, 2000. 61 p. (Documento, 85).

Ciênc. agrotec., Lavras, v. 29, n. 6, p. 1265-1271, nov./dez., 2005 
EUCLIDES FILHO, K.; EUCLIDES, V. P. B.; FIGUEREDO, G. R. Avaliação de animais Nelore e seus mestiços com Charolês, Fleckvie e Chianina, em três dietas: I. ganho de peso e conversão alimentar. Revista Brasileira de Zootecnia, Viçosa, v. 26, n. 1, p. 66-72, 1997.

EUCLIDES FILHO, K.; EUCLIDES, V. P. B.; FIGUEREDO, G. R. Eficiência bionutricional de animais Nelore e seus mestiços com Simental e Aberdeen Angus, em duas dietas. Revista Brasileira de Zootecnia, Viçosa, v. 30, n. 1, p. 77 82, 2001.

EUCLIDES FILHO, K.; FIGUEREDO, G. R.; EUCLIDES, V. P. B. Eficiência bionutricional de animais da raça Nelore e seus mestiços com Caracu, Angus e Simental. Revista Brasileira de Zootecnia, Viçosa, v. 31, n. 1, p. 331-334, 2002.

EUCLIDES FILHO, K.; FIGUEREDO, G. R.; EUCLIDES, V. $\mathrm{P}$. B. Desempenho de diferentes grupos genéticos de bovino de corte em confinamento. Revista Brasileira de Zootecnia, Viçosa, v. 32, n. 5, p. 1114-1122, 2003.

EUCLIDES, V. P. B.; EUCLIDES FILHO, K.; ARRUDA, Z. J. Desempenho de novilhos em pastagem de Brachiaria decumbens submetidos a diferentes regimes alimentares. Revista Brasileira de Zootecnia, Viçosa, v. 27, n. 2, p. 246254, 1998.

FORBES, J. M. Voluntary food intake and diet selection in farm animals. Wallingford: CAB International, 1995. 532 p.

FRISCH, J. E.; VERCOE, J. E. Food intake, eating rate, weight gains, metabolic rates and efficiency of feed utilization in Bos taurus and Bos indicus crosbreed cattle. Animal production, Edinburgh, v. 24, n. 1, p. 343-358, 1977.

HUNTER, R. A.; SIEBERT, B. D. Utilization of low-quality roughage by Bos Taurus and Bos indicus cattle: I. rumen digestion. British Journal of Nutrition, London, v. 53, p. 637-648, 1985a.
HUNTER, R. A.; SIEBERT, B. D. Utilization of low-quality roughage by Bos Taurus and Bos indicus cattle: II. effect of rumen degradable nitrogen and sulphur on voluntary food intake and rumen characteristics. British Journal of Nutrition, London, v. 53, p. 649-656, 1985 b.

LANA, R. P. Sistema Viçosa de formulação de rações. Viçosa: UFV, 2000. $60 \mathrm{p}$.

LANA, R. P.; GOMES JÚNIOR, P. Sistema de suplementação alimentar para bovinos de corte em pastejo: validação. Revista Brasileira de Zootecnia, Viçosa, v. 31, n. 1, p. 451-459, 2002. Suplemento.

McCOLLUN, F. T.; HORN, G. W. Protein supplementation of grazing livestock: a review. Professional Animal Scientist, [S.1.], v. 6, p. 1-16, 1990.

MOORE, J. E.; BRANT, M. H.; KUNKLE, W. E. Effects of supplementation on voluntary forage intake, diet digestibility, and animal performance. Journal of Animal Science, Champaign, v. 77, p. 122-135, 1999. Supplement 2.

SILVA, D. J.; QUEIROZ, A. C. Análise de alimentos: métodos químicos e biológicos. Viçosa: UFV, 2002. 235 p.

TILLEY, J. M. A.; TERRY, R. A. A two-stage technique for the in vitro digestion of forage crops. Journal of British Grassland Society, Oxford, v. 18, p. 104-111, 1963.

UNIVERSIDADE FEDERAL DE VIÇOSA.SAEG-Sistema de Análises Estatísticas e Genéticas: manual do usuário. Versão 8.0. Viçosa, 2000. 142 p.

VERCOE, J. E. Breed and nutritional effects on the composition of faeces, and plasma from Hereford and Brahman x Hereford steers fed on high and low quality diets. Australian Journal of Agricultural Research, Melbourne, v. 18, n. 10, p. 1003-1013, 1967. 